\title{
Normative approaches to structural design calculations in a non-linear framework
}

\author{
Oleg Mkrtychev ${ }^{1}$, Guram Dzhinchvelashvili ${ }^{1}$, and Marina Busalova ${ }^{1, *}$ \\ ${ }^{1}$ Moscow State University of Civil Engineering, Research laboratory "Safety and Seismic Resistance \\ of Structures”, 129337 Moscow, Russia
}

\begin{abstract}
This article considers the issue of taking non-linearity into account when performing design calculations for buildings and structures exposed to intense seismic impact. The existing rule codex 14.13330.2014 «SNIP II-7-81* "Construction in seismic areas" regulates the possible behavior beyond the elastic range with by introducing a damage tolerance factor. However, extensive research conducted by the authors of this article and other experts in the seismic resistance theory reveal that the values of this factor for buildings of various structural layouts must be corrected. The paper investigates the behavior of multi-element systems exposed to seismic impact, the structural layouts of them being as follows: wallsupported slab systems, reinforced concrete rigid frame buildings and buildings with a metal space frame. Calculations were made which describe the behavior of the buildings exposed to an intense earthquake modeled in the form of accelerograms standardized as 8 points on the MSK 64 scale. The calculations were performed using the LS-DYNA software package which makes use of the direct dynamic method and provides means for making all the calculations in the time domain and for taking the physical, geometric and structural non-linearity into account. The results obtained indicate that wall-supported slab buildings and rigid frame RC buildings collapse due to emerging and developing plastic deformations, while metal frame buildings lose their stability before their bearing capability is exhausted. The research carried out by the authors enabled them to pinpoint the reason for the discrepancy between the obtained values of the damage tolerance factor and the values stipulated by the regulation, as well as to draw a conclusion that these values should be refined.
\end{abstract}

\section{Introduction}

Seismic-resistant buildings must ensure safety of human life and preservation of tangible assets and cultural artifacts even when exposed to extremely intense earthquakes. In many cases this can be achieved without requiring that buildings or structures remain completely intact, as cracks and local damage may arise. But if human lives and the most valuable equipment are retained, such buildings and structures can be considered earthquakeresistant $[1,2]$.

*Corresponding author: marina8busalova@gmail.com 
When structures should be capable of resisting seismic impact beyond elasticity limits, it is usually acceptable that their resistance to seismic stress can be designed to be less than the stress corresponding to the linear elastic response.

Analysis of non-elastic behavior of structures should be left out from the design effort. For this, the current design regulation takes account of the capability of a structure to dissipate energy, which is driven by mainly elastoplastic behavior of its elements and other phenomena. Specifically, the regulation provides for an elasticity analysis based on the design response spectrum and introduces a reduction factor for the elastic response spectrum.

The effort of numerous researchers resulted in methods of using the above mentioned framework for conducting performance calculations of non-linear oscillations of buildings exposed to seismic impact. To determine the seismic design loads, most countries' regulations make use of reduction methodology when considering nonlinear effects. This approach is generally accepted, however, the latest research in seismic resistant construction has discovered a possibly deficient seismic capacity of the buildings and structures designed under this methodology.

\section{The rationale behind the damage tolerance factor}

The generally accepted design calculation of seismic resistance is based on matching the forces or strains driven by external load with maximum permissible values of internal forces (or strains) which can manifest themselves in the relevant sections of the structure. The values of maximum allowable stress in inside dimensions of a structure vary depending on whether we consider solely elastic behaviour of the material or also take account of its plastic deformations.

In fact, it is impossible to say anything certain about seismic resilience of a designed structural system. Hence, we obtain a structure with an unknown degree of seismic capacity.

Structural design which accounts for plastic and non-linear behavior or even for destruction of individual structural elements requires usage of more complex mechanical and mathematical models and theories, i.e. assumptions of controlled damage. Also, regard must be had to the redistribution of forces within the structure, the cause of which are the emerging zones of plastic deformations. But the principle of matching external and internal forces remains a criterion for the assessment of a structure's bearing capacity in all cases.

The regulations [3] allow for development of non-elastic (plastic) deformations for most buildings and structures. Non-linear behavior is taken care of by multiplying the seismic forces by the $K_{1}$ factor which absorbs the allowable damage. For instance, $\mathrm{K}_{1}=0.22$ is used for monolithic wall-supported slab buildings whose structures can tolerate residual deformations and damage detrimental to normal operation but still provide safety for human life and equipment. Numerous experts in seismic resistant construction deem the values of $K_{1}$ presented in Table 3 in [3] ill-founded.

The necessity to reconsider the $K_{1}$ factor manifests itself, firstly, when data are analyzed for calculating the seismic capacity of a building using the regulations currently in effect. Research reveals that misuse of the damage tolerance factor may result in reduced seismic resilience of structures and their possible overall collapse [4]. Secondly, the authors have done research of buildings with different types of structures in a non-linear dynamic framework and arrived at the conclusion that the $K_{1}$ factor must assume values other than those stipulated in the regulation [3].

The findings of this research are presented below. 


\subsection{Multi-element wall-supported slab system}

Let us consider a 27-storey monolithic tower block $H=81.6 \mathrm{~m}$ high with an elevator shaft at the center (Figure 1). The building was designed to be erected in a seismic area. The calculation under the response spectrum theory [3] indicates that the seismic capacity of the building is 9 points on the MSK-64 scale.

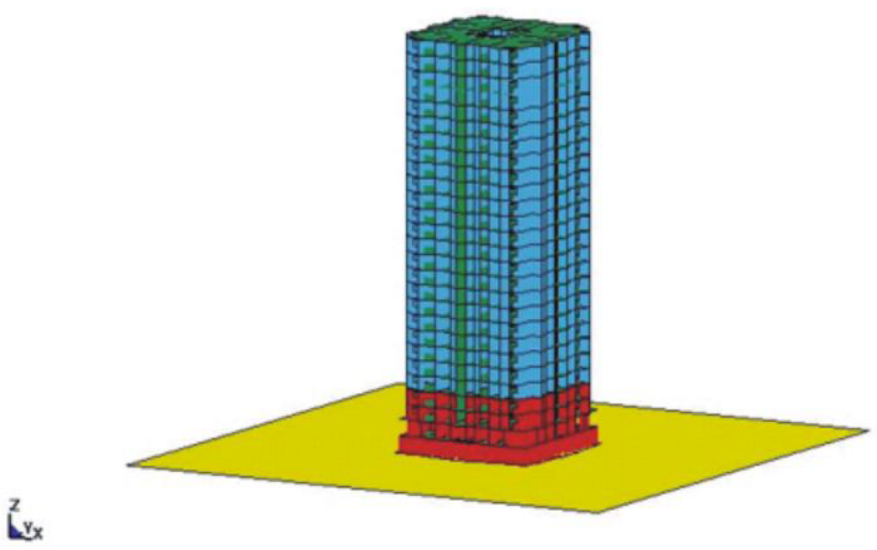

Fig. 1. Design diagram of the multistorey monolithic building.

Now the building is exposed to an external impact along the horizontal axis $X$ which is set by the accelerogram presented in Figure 2.

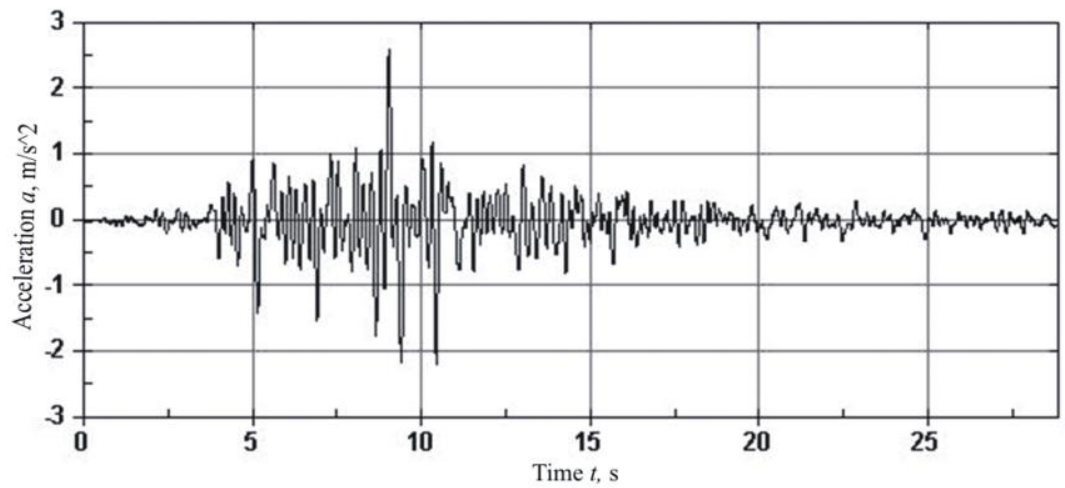

Fig. 2. Accelerogram of the original impact.

Figure 3 displays the motions of the point $w$ at the level of the upper floor slab for a problem in a linear (curve 1) and nonlinear (curves 2 and 3) setups. The non-linear setup presumes that the material deforms under the Prandtl diagram with the initial modulus of elasticity being $E=3 \cdot 10^{4} \mathrm{MPa}$. Further, options with incremental reduction of the yield point of the material $\sigma_{\mathrm{T}}$, are considered, and this is the way how increased intensity of non-linear effects is modeled. The yield point $\sigma_{\mathrm{T}}=20 \mathrm{MPa}$ is reflected by curve 2 , while $\sigma_{\mathrm{T}}=13 \mathrm{MPa}$ is depicted by curve 3 . 


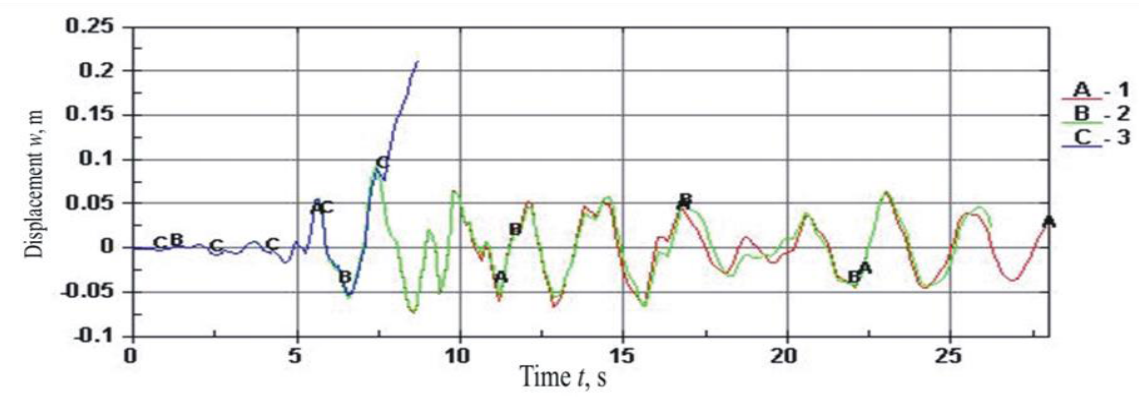

Fig. 3. Motion of the $w$ point at the level of the upper floor slab.

$\sigma_{\mathrm{T}}=13 \mathrm{MPa}$ at the time point $t=7.6 \mathrm{~s}$ triggers progressive collapse of the building (see curve 3 ).

Figure 3 displays that design calculations made for multistorey monolithic buildings in a non-linear setup do not demonstrate any reduction in the displacement amplitude of the structure's characteristic points. The reason for this is that plastic deformations can be spotted in elements insignificant in number compared to the total number of elements (Figure 4). On the whole, the stiffness of the structure barely changes till collapse.

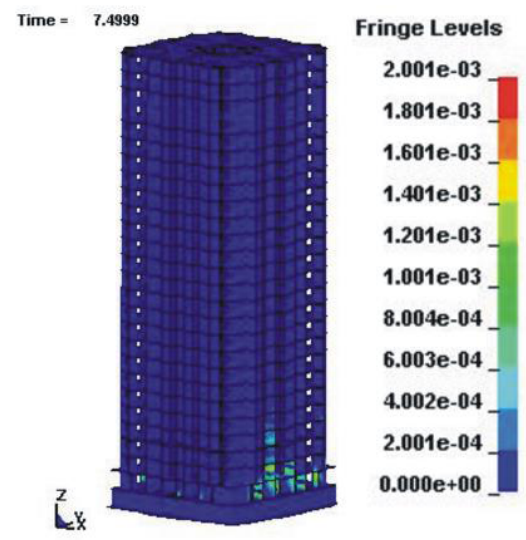

Fig. 4. Isofields of plastic deformations prior to collapse $(t=7.6 \mathrm{~s})$.

Seismic loads assigned to the type of buildings under consideration must not be scaled down, and the $K_{1}$ factor must not be applied.

If damage tolerance is taken into account in a linear calculation, seismic impact may be reduced only in case a surplus of bearing capacity can be proven and stress can be redistributed between the elements. E.g., design regulations of foreign countries provide for load reduction (to a much lower extent) only for buildings and structures of specific structural layouts after an in-depth analysis of structural behavior.

Ultimately, the buildings of specific structural layouts designed in accordance with the rule codex 14.13330.2014 SNIP II-7-81* "Construction in seismic areas" may exhibit deficiency of seismic capacity up to 2 points. For instance, Russian 9-point zones are home to buildings able to tolerate 7 points only. 


\subsection{Reinforced concrete rigid frame building}

Let is consider a 5-storey reinforced concrete monolithic building, the structural layout of which is a complete space frame (exterior walls non-bearing) with column spacing being 6 meters in both directions (Figure 5). Column section is $400 \times 400 \mathrm{~mm}$, beam section is $500 \times 300 \mathrm{~mm}$.

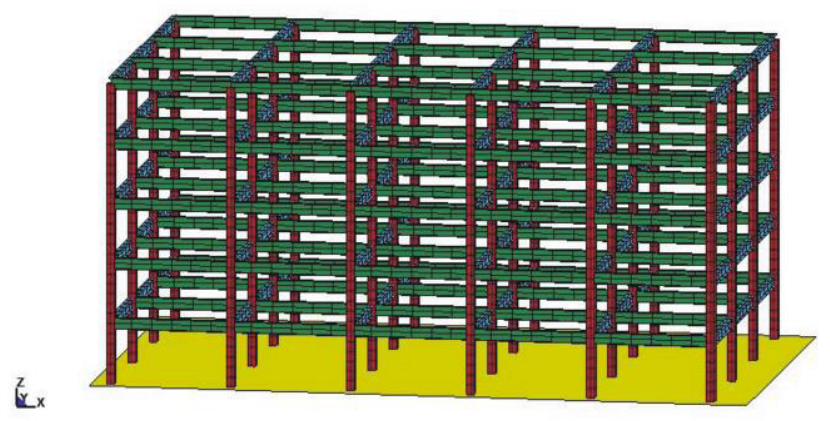

Fig. 5. Design model of the rigid frame building.

The building is exposed to an external impact set by the accelerogram standardized as 8 poins on the MSK-64 scale (see Figure 2).

Figure 6 displays the motions of the $w$ point on the roofing level in a linear and nonlinear setup. The non-linear setup presumes that the material deforms under the Prandtl diagram with the initial modulus of elasticity being $E=3 \cdot 10^{4} \mathrm{MPa}$. The maximum allowed value of plastic deformations in introduced into the calculation [5,6,7]. Further, options with incremental reduction of the yield point of the material $\sigma_{\mathrm{T}}$ are considered, and this is the way how the increasing intensity of non-linear effects is modelled. Curve 1 denotes elastic behavior, curve $2-\sigma_{\mathrm{T}}=40 \mathrm{MPa}$ yield point; curve $3-\sigma_{\mathrm{T}}=30 \mathrm{MPa}$ yield point; curve $4-\sigma_{\mathrm{T}}=29 \mathrm{MPa}$ yield point.

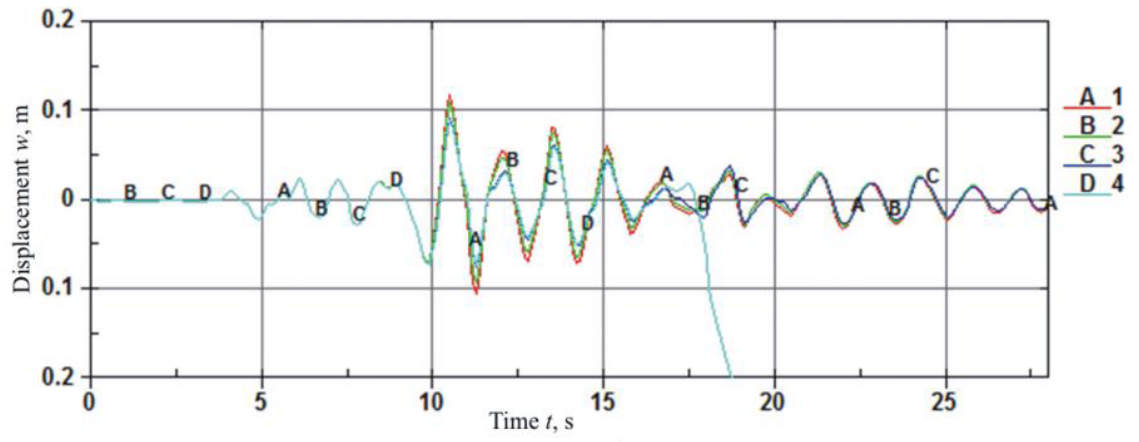

Fig. 6. Motions of the $w$-point on the roofing level.

$\sigma_{\mathrm{T}}=29 \mathrm{MPa}$ at the time point of 17 seconds triggers progressive collapse of the building (see curve 4). Figure 7 displays the building at the time point $t=18 \mathrm{~s}$ along with the isofields of maximum stress intensity $\sigma_{i}$ in the elements. 


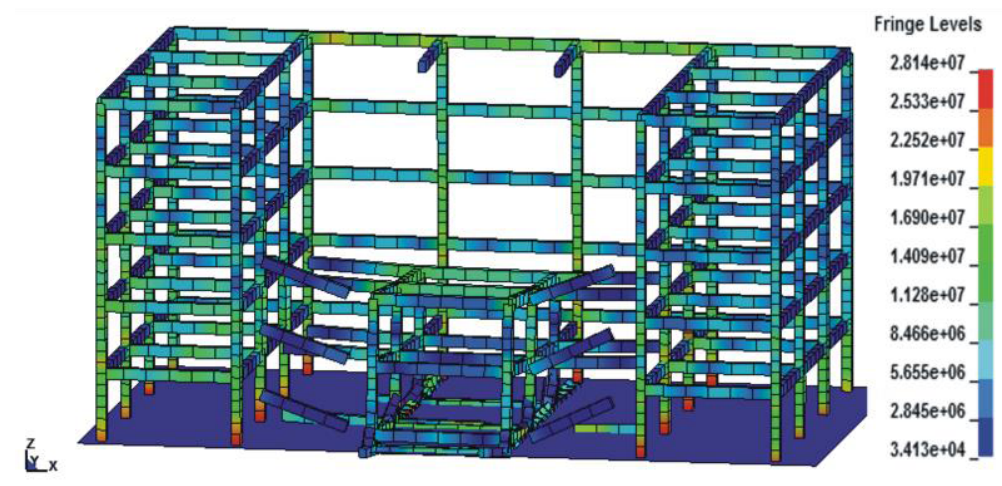

Fig. 7. Collapse of the building.

The research undertaken enables us to draw a conclusion that this type of reinforced concrete rigid frame buildings dictates that the reduction factor to take account of nonlinear behavior of structures be considered equal to 1.3. The factor which absorbs the allowable damage to buildings and structures (damage tolerance factor) must be set to 0.77 .

\subsection{A building with a space metal frame}

Now we are going to consider the same seismic impact and the response of a 5-storey building to it. The building's structural layout is a complete rigid space metal frame (exterior walls nonbearing) with the identical $6 \mathrm{~m}$ spacing between the columns in both directions (see Figure 5). The columns and beams are I-shaped.

Figure 8 displays the motions of the point $w$ at the roofing level for a problem in a linear and non-linear setups. The non-linear setup presumes that the material deforms under the Prandtl diagram with the initial modulus of elasticity being $E=2.1 \mathrm{MPa}$. The limit value of intensity of plastic deformations is assumed to be $\varepsilon_{i}=0.08$. Options with incremental reduction of the yield point of the material $\sigma_{\mathrm{T}}$ are considered. Curve 1 denotes elastic behavior; curve $2-$ yield point $\sigma_{\mathrm{T}}=300 \mathrm{MPa}$; curve 3 - yield point $\sigma_{\mathrm{T}}=200 \mathrm{MPa}$; curve $4-$ yield point $\sigma_{\mathrm{T}}=150 \mathrm{MPa}$.

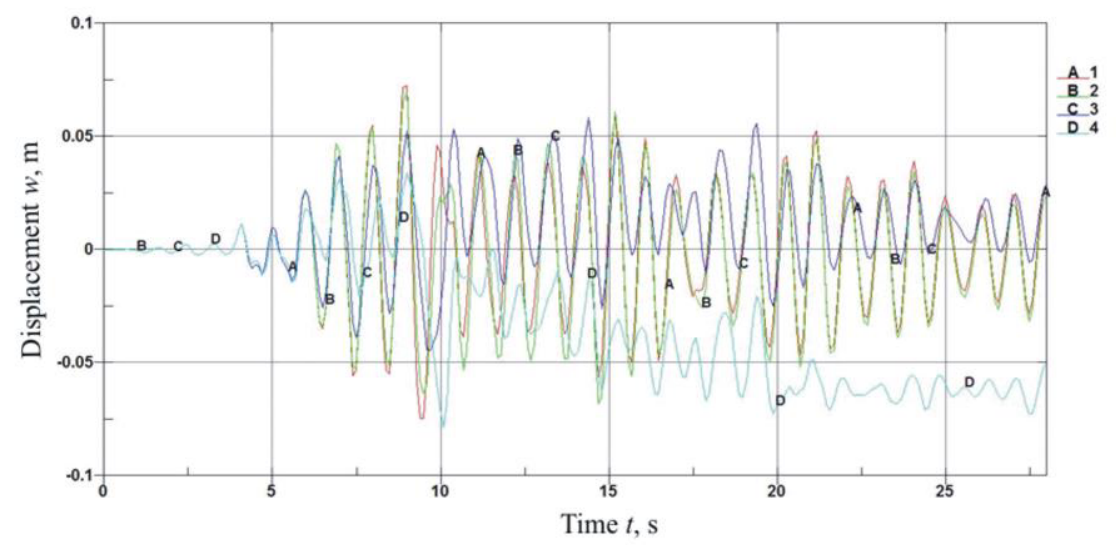

Fig. 8. Motions of the $w$ point on the roofing level.

It should be noted that the load-bearing metal frame of the building exposed to an earthquake may lose stability before the bearing capacity of the system is exhausted as 
plastic deformations reach their limtis. Thus, if $\sigma_{\mathrm{T}}=130 \mathrm{MPa}$ the structure will lose stability altogether at the time point of 13 seconds. Figure 9 depicts the buckling and the isofields of motions along the $Y$ axis.
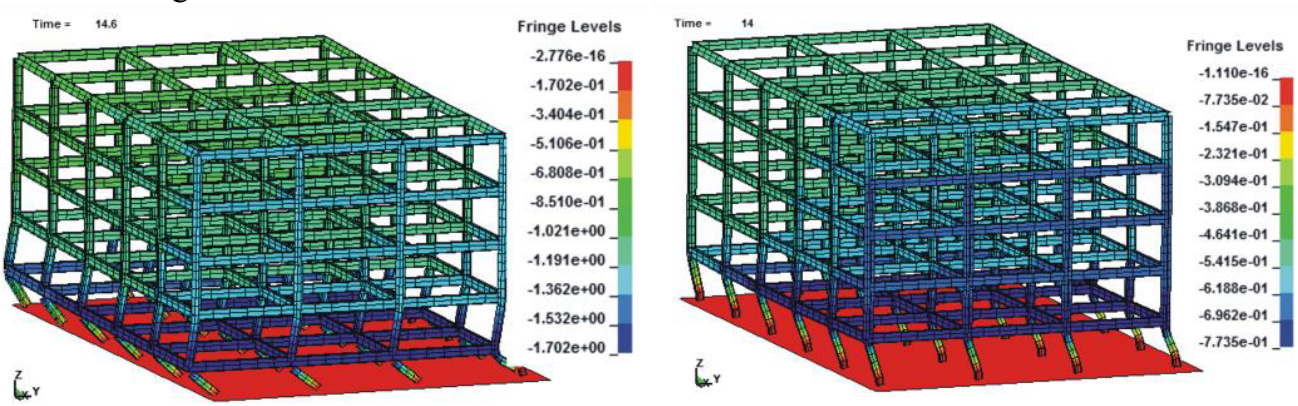

Fig. 9. Overall failure of the building: a) $t=14 \mathrm{~s}$; b) $t=14.6 \mathrm{~s}$.

The output evaluation goes to show that the building in question with a complete steel frame (exterior walls nonbearing) dictates that the reduction factor to take account of nonlinear behavior of structures should be set to 5 . The coefficient which absorbs the allowable damage to buildings and structures (damage tolerance factor) is equal to 0,2 .

\section{Conclusions}

The authors used the output of calculations made for the buildings of different structural layouts to conduct additional research, which enabled them to substantiate why the values of the K1 factor are different from the regulatory values (Table 1) [3,8].

Table 1. $K_{l}$ comparative table.

\begin{tabular}{|c|c|c|c|c|}
\hline & Structural layout & $\begin{array}{c}\boldsymbol{K}_{\boldsymbol{I}} \text { factor (SNIP II- } \\
\mathbf{7 - 8 1 ^ { * }} \text { ) }\end{array}$ & $\begin{array}{c}\text { Values obtained } \\
\text { from a direct } \\
\text { nonlinear } \\
\text { analysis }\end{array}$ & $\begin{array}{c}\text { Overestimation } \\
\text { of bearing } \\
\text { capacity, times }\end{array}$ \\
\hline 1 & $\begin{array}{c}\text { Rigid steel framework } \\
\text { buildings }\end{array}$ & 0.25 & 0.2 & 0.8 \\
\hline 2 & $\begin{array}{c}\text { Buildigs with a } \\
\text { monolithic RC rigid } \\
\text { framework }\end{array}$ & 0.35 & 0.77 & 2.2 \\
\hline 3 & $\begin{array}{c}\text { Monolithic wall- } \\
\text { supported slab buildings }\end{array}$ & 0.22 & 1 & 4.5 \\
\hline
\end{tabular}

Consequently, the reduction factor is determined unreasonably in most cases. More research in this domain along with the use of non-linear static and dynamic methods is necessary. The findings of such research should form the basis for the next generation regulations.

\section{References}

1. A. N. Akhvelediani, Theorems on logical collapse in terms of the theory of limit equilibrium of plastic systems (Russika encyclopaedic foundation, Saint Petersburg, 2011)

2. O. V. Mkrtychev, G. A. Dzhinchvelashvili, Science and transportation, E 2, 8 (2002)

3. SP 14.13330.2014 SNIP II-7-81. Construction in Seismic Areas (Analitik, Moscow, 2014) 
4. O. V. Mkrtychev, V. B. Dorozhinskiy, D. S. Sidorov, Proceedings of Moscow State University of Civil Engineering 12, 10 (2015)

5. O. V. Mkrtychev Safety of buildings and facilities exposed to seismic and emergency impact (Moscow State University of Civil Engineering, Moscow, 2010)

6. V. A. Rzhevsky $A$ research on non-stationary elastoplastic systems exposed to complex seismic impact (Stroyizdat, Moscow, 1988)

7. O. V. Mkrtychev, G. A. Dzhinchvelashvili, M. S. Busalova, Proceedings of Moscow State University of Civil Engineering 12, 7 (2013)

8. O. V. Mkrtychev, G. A. Dzhinchvelashvili Accounting for non-linearity in the seismic resistance theory (hypotheses and fallacies) (Moscow State University of Civil Engineering, Moscow, 2012) 